\title{
Integrating crop redistribution and improved managements could meet China's food demand with lower environmental costs
}

\section{Zihan Wang}

China Agricultural University

\section{Yulong Yin}

College of Resources \& Environmental Sciences, China Agricultural University, Beijing 100193, China

\section{Yingcheng Wang}

China Agricultural University

\section{Xingshuai Tian}

China Agricultural University

\section{Hao Ying}

China Agricultural University

\section{Qingsong Zhang}

College of Resources \& Environmental Sciences, China Agricultural University, Beijing 100193, China https://orcid.org/0000-0002-2481-8961

\section{Yanfang Xue}

Shandong Academy of Agricultural Sciences

\section{Feng Zhou}

Peking University https://orcid.org/0000-0001-6122-0611

\section{Mingxi Du}

Department of Geography, Montreal, McGill University, Quebec H3A 0B9

\section{Lin Ma}

Center for Agricultural Resources Research, Institute of Genetic and Developmental Biology, The Chinese Academy of Sciences https://orcid.org/0000-0003-1761-0158

\section{Fusuo Zhang}

https://orcid.org/0000-0001-8971-0129

Zhenling Cui ( $\nabla$ cuizl@cau.edu.cn )

China Agricultural University https://orcid.org/0000-0002-5419-3771

\section{Article}

Keywords: 
Posted Date: January 6th, 2022

DOI: https://doi.org/10.21203/rs.3.rs-1202314/v1

License: (c) (i) This work is licensed under a Creative Commons Attribution 4.0 International License. Read Full License 


\section{Integrating crop redistribution and improved managements could meet China's food demand with lower environmental costs}

Zihan Wang ${ }^{1,6}$, Yulong Yin ${ }^{1,6}$, Yingcheng Wang ${ }^{1}$, Xingshuai Tian ${ }^{1}$, Hao Ying ${ }^{1}$, Qingsong Zhang ${ }^{1}$, Yanfang Xue ${ }^{2}$, Feng Zhou ${ }^{3}$, Mingxi Du ${ }^{4}$, Lin $\mathrm{Ma}^{5}$, Fusuo Zhang ${ }^{1}$, Zhenling Cui ${ }^{*}$

${ }^{1}$ College of Resources and Environmental Sciences, National Academy of Agriculture Green Development, Key Laboratory of Plant-Soil Interactions, Ministry of Education, China Agricultural University, Beijing 100193, China

${ }^{2}$ Maize Research Institute, Shandong Academy of Agricultural Sciences, Jinan, China. ${ }^{3}$ Sino-France Institute of Earth Systems Science, Laboratory for Earth Surface Processes, College of Urban and Environmental Sciences, Peking University, Beijing 100871, China.

${ }^{4}$ School of Public Policy and Administration, Xi'an Jiaotong University, Xi'an 710049, China

${ }^{5}$ Key Laboratory of Agricultural Water Resources, Center for Agricultural Resources Research, Institute of Genetics and Developmental Biology, Chinese Academy of Sciences, Shijiazhuang, China

${ }^{6}$ These authors contributed equally: Zihan Wang, Yulong Yin

* Corresponding author:

cuizl@cau.edu.cn (Zhenling Cui) 


\section{Abstract}

Sustainably feeding the growing population in China attracts attention globally.

Despite practices success, producing enough food to simultaneously address resource and pollution problems has been infeasible. To assess how to achieve this goal in 2035, we created a pathway that synergistic combining improved managements and cropland redistribution based on 11.1 million farmer surveys and 4,272 georeferenced field observations. Here, we firstly selected the practices of top $10 \%$ performers in crop yield and nitrogen $(\mathrm{N})$ efficiency as crop-specific attainable improved managements at the county level. The optimized crop distribution within improved managements was then performed to minimize inputs ( $\mathrm{N}$ and phosphorus fertilizer, irrigation water) or environmental impacts (reactive $\mathrm{N}[\mathrm{Nr}]$ loss and greenhouse gas [GHG] emissions). We identified that combing improved managements and cropland redistribution could produce enough food demands in 2035 , with $24 \%$ more production compared to 2012. It also reduced the inputs and environmental impacts in a range of $19 \%-35 \%$, mainly sourced from the central and eastern coastal areas by improved productivity and diminished cropland of fruit and vegetables. These findings highlight the necessity for a synergistic combination of measures to sustainably feed the growing population and establish a more realistic and effective policy. 


\section{Introduction}

Sustainably feeding a growing population with optimized agriculture inputs (particularly fertilizer and irrigation water) and minimized environmental impacts is a huge challenge amid climate change ${ }^{1,2}$. These challenges may grow in the future because global food demand is expected to increase by $35-56 \%$ between 2001 and $2050^{3}$. There are several apprehensions about how to sustainably feed growing population. First, the current yield increasing trajectories will discontinue and reach yield potential, and there is evidence of rice in eastern Asia and wheat in northwest Europe reached a yield plateau ${ }^{4}$. Second, negative environmental impact is a concern because agriculture expends $89 \%$ of the chemical fertilizer ${ }^{5}$, uses $>60 \%$ of the fresh water ${ }^{6}$, and is recognized as the main source of reactive nitrogen $(\mathrm{Nr})$ loss, contributing $90 \%$ of the global anthropogenic $\mathrm{NH}_{3}$ emissions and $60 \%$ of $\mathrm{N}_{2} \mathrm{O}^{7,8}$. More than half of countries already exceed the planetary boundaries for nitrogen $(\mathrm{N})$, phosphorus (P), and greenhouse gas (GHG) emissions by cropping systems ${ }^{9-11}$. Third, the improved agriculture managements and crop configuration must be tailored to specific local environments, economic development, and social factors ${ }^{12}$, while the current crop distribution is determined mainly by native culture and dietary preferences.

China is a rapidly developing country, where $20 \%$ of the world's population is fed with $8 \%$ of the world's arable land, and the agricultural system relies heavily on high inputs ${ }^{5}$. Recently, it is increasingly recognized that China land use patterns have global ramifications through international trade, such as import $66 \%$ of the soy traded 
on the international market ${ }^{13}$. A few studies focusing on agriculture sustainability have identified opportunities to simultaneously produce more with fewer inputs and minimal environmental impact by closing the yield gap ${ }^{13-15}$ through improving management practices ${ }^{16,17}$. Global research and part of the region (e.g., India) suggests a strong mitigation potential through optimized crop distribution ${ }^{2,18}$. Although these strategies provide benefits individually, the roadmap to sustainable food security is unclear. Can China produce enough food to feed the growing population by 2035 on existing farmland? If so, can the agricultural inputs and environmental costs of intensive agriculture be reduced?

Preparing a detailed roadmap toward producing enough food with optimized inputs and lower costs in China remains a high priority. Although many estimates of individual techniques or management strategies have been reported ${ }^{19,20}$, a national, spatially explicit strategy that maximizes production potential and can meet the food demand sustainably is lacking. The key reason for this is that most studies have not reported the spatially explicit attainable crop yield potential and their corresponding agricultural inputs and environmental costs ${ }^{15}$. A strategy for an optimized crop configuration based on the current producer's managements ${ }^{2,18}$, ignoring technique potential, would limit the comprehensive assessment of food production in the future. This highlights the necessity to synergistically combine improved local management practices and optimized crop distribution. This is particularly important in rapidly developing regions in which substantial yield increases have been achieved from green-revolution technologies by managing high-input, low-efficiency systems ${ }^{17,19}$. 
This study seeks to provide an integrated and transdisciplinary approach that leverages existing locally available management practices to integrate food security, resource conservation, and environmental sustainability. We developed a new dataset from a survey of farmers (11.1 million farmers), published articles $(4,272$ observations), and statistical data to map the crop-specific county-level yield and inputs ( $\mathrm{N}$ and $\mathrm{P}$ fertilizer and irrigation water), $\mathrm{Nr}$ losses $\left(\mathrm{NH}_{3}\right.$ plus $\mathrm{NO}_{3}{ }^{-}$leaching and $\mathrm{N}_{2} \mathrm{O}$ ), and GHG emissions in China. We first estimated the attainable yield potential and related inputs and environmental costs, defined as attainable improved managements. Then, we explored the potential to optimize crop distribution with this improved managements. We discovered that no single measure was sufficient to secure food demand by 2035 , but that a synergistic combination of optimized crop distribution and improved managements would produce enough food with less agriculture input, Nr loss, and GHG emissions. Our study seeks the development of sustainable agriculture and provides a feasible sustainable pathway for the future.

\section{Results and discussion}

China's food demand in 2035. We first explored whether food demand (includes the crop consumed as food, feed, and processing, summarized as food demand in this study) in 2035 could be met using the existing farmland in China. The population in China is expected to increase from 1.36 to 1.46 billion and the urbanization rate will increase from $53 \%$ to $72 \%$ during $2012-2035^{21}$. Food demand in 2035 has been estimated to be 2,216 (2,042-2,389) million tons (Mt; Table S1), 18\% (9\%-28\%) more than in 2018, and 31\% (21\%-41\%) more than consumed in 2012 (see Methods). The 
major growth in food demand came from soybeans, from $71 \mathrm{Mt}$ in 2012 to 125 (119132) Mt in 2035 to feed growing livestock populations. Estimated protein demand increased by $41 \%$ from 109 to 153 (142-164) Mt during 2012-2035 due to the relatively higher protein content of soybean (see Method; Table S1). These protein demands in 2035 are $69 \%(57 \%-81 \%)$ greater than domestic production in $2012^{22}$, indicating a major challenge to achieve food self-sufficiency (defined as the ratio of domestic food production to consumption) in China.

Production could be maximized by shifting crops to suitable areas and maintaining the current arable land. The large variation in productivity among crops and counties in China (Fig. S2) provides the potential for improvements by redistributing crops. We used a linear programming approach to determine maximum protein production, with the constraints that sowing area and irrigation water in each county would not increase relative to 2012. Maximum protein production using the optimized crop distribution was estimated to be 145 (139-153) Mt (see Methods). This values is 6.0\% (1.3\%-11.9\%) higher than $137 \mathrm{Mt}$ protein demand in 2018, however, it is still $5.1 \%$ $(0.0 \%-9.3 \%)$ lower than the 2035 demand (Fig. 1a). These results underscore the massive increase in food demand in 2035, which has outstripped the production potential by using crop redistribution alone.

We further explored the potential for production and mitigation by combining crop redistribution and closing the yield gap (defined as the difference between the yield of improved managements and the yields actually achieved by farmers in this study).

Our previous research determined the crop-specific county-level potential of 
attainable yield and $\mathrm{N}$ efficiency, which selected the prime smallholders that ranked in the top $68-100^{\text {th }}$ percentile of crop yield and $\mathrm{N}$ efficiency in each county ${ }^{15}$. These results came from the survey of 11.1 million farmers, representing $>95 \%$ of the cropland in China. Previous studies have indicated that improved management practices (e.g., integrated soil-crop system managements; Chen et al., 2014; Cui et al., 2018) can increase cereal crop yields to the level of the top producers. These local prime producers enhance crop yields by $15-35 \%$ and reduce $\mathrm{N}$ inputs by $16-24 \%$ across crops and counties ${ }^{15}$. If all farmers achieved the prime producers' yield, they were estimated to produce 129 (124-134) Mt protein under the current crop configuration and existing farmland, which is $15.8 \%(12.5 \%-19.1 \%)$ lower than the 2035 demand (Fig. 1a).

\section{How China produce enough food by 2035 while minimizing agriculture inputs}

and environmental impacts. We developed a random forest (RF) regression model to simulate crop-specific county-level $\mathrm{Nr}$ loss of prime producers (see Methods) to estimate the spatial heterogeneity of $\mathrm{Nr}$ loss via $\mathrm{N}_{2} \mathrm{O}$ emissions, $\mathrm{NH}_{3}$ volatilization, $\mathrm{NO}_{3}{ }^{-}$leaching, and GHG emissions from 4,272 in-situ observations. Substantial variation was observed for $\mathrm{Nr}$ loss, with an average of $0.007 \mathrm{~kg} \mathrm{~N} \mathrm{~kg}^{-1}$ yield (range from $0.002 \mathrm{~kg} \mathrm{~N} \mathrm{~kg}^{-1}$ for sugarcane to $0.02 \mathrm{~kg} \mathrm{~N} \mathrm{~kg}^{-1}$ for soybean) aggregated from all 11 crops and an average of $56 \mathrm{~kg} \mathrm{~N} \mathrm{ha}^{-1}\left(19-112 \mathrm{~kg} \mathrm{~N} \mathrm{ha}^{-1}\right)$ across 2036 counties (Fig. S2). We further estimated $\mathrm{GHG}$ emissions from direct $\mathrm{N}_{2} \mathrm{O}$ emissions and indirect emissions from $\mathrm{NH}_{3}$ volatilization and $\mathrm{NO}_{3}{ }^{-}$leaching. The GHG emissions averaged $0.21 \mathrm{~kg} \mathrm{CO}_{2} \mathrm{eq} \mathrm{kg}^{-1}$ yield (from $0.05 \mathrm{~kg} \mathrm{CO}_{2}$ eq $\mathrm{kg}^{-1}$ for sugarcane to 0.46 
$\mathrm{kg} \mathrm{CO}_{2}$ eq $\mathrm{kg}^{-1}$ for soybean) and averaged $1.6 \mathrm{t} \mathrm{CO}_{2} \mathrm{eq} \mathrm{ha}^{-1}\left(0.4-4.2\right.$ t CO2 eq ha $\left.{ }^{-1}\right)$ across the 2,036 counties (Fig. S1).

(a)

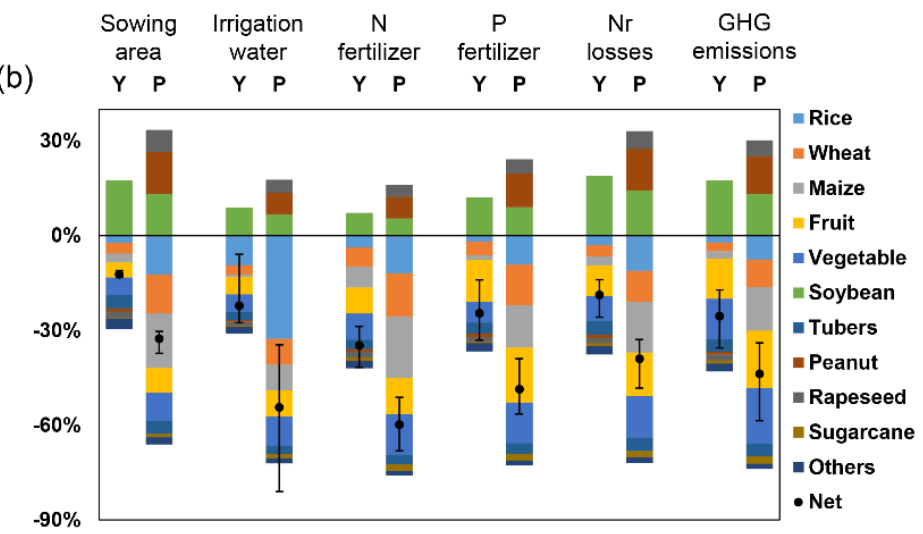

(c)

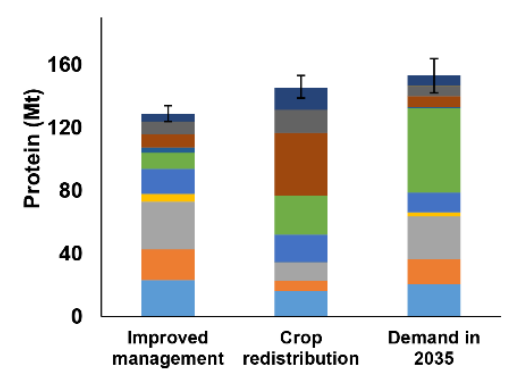

(b)

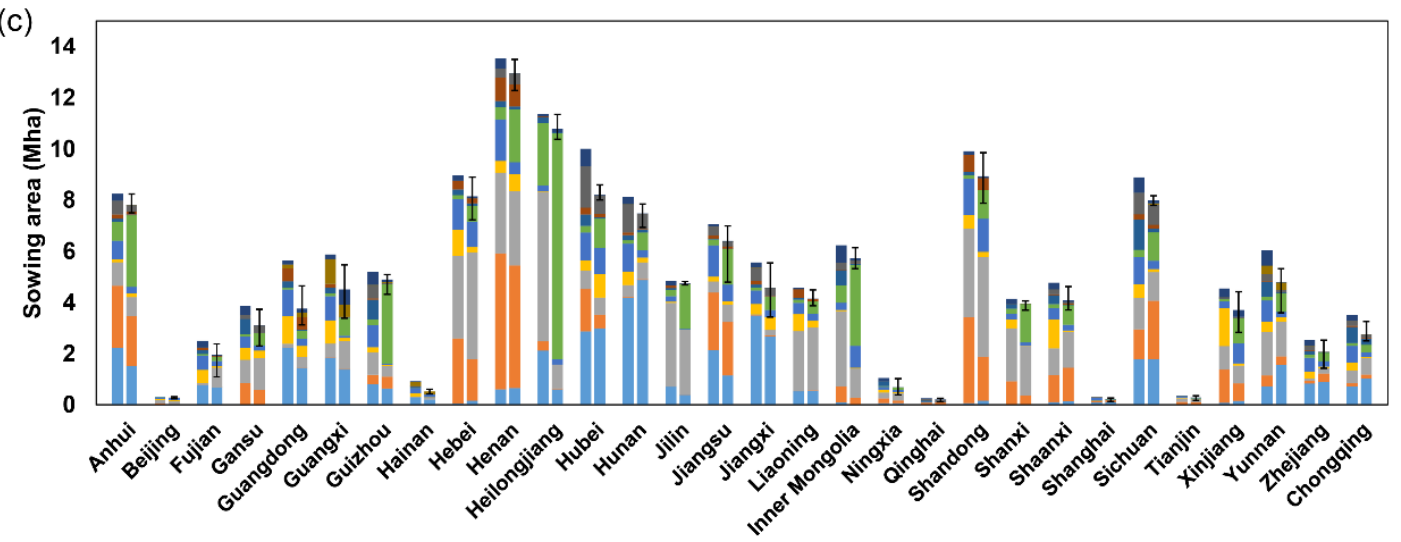

Fig. 1. Outcomes under optimized crop distribution and attainable improved managements. (a) Protein demand of 2035 and production under individual measures. The error bars reflect the expected lowest and highest estimations under 10,000 Monte Carlo sampling simulations. (b) The outcomes (including sowing area, irrigation water, $\mathrm{N}$ fertilizer use, $\mathrm{P}$ fertilizer use, Nr loss, and GHG emission) of combining measures. Columns of $\mathrm{Y}$ and $\mathrm{P}$ show the average outcome of the five optimization objectives for scenarios $\mathrm{Y}_{2035}$ and $\mathrm{P}_{2035}$ (see Methods) compare to 2012, respectively. Columns with positive (or negative) percentages indicate the increased (or decrease) effect due to the combining measures. Black dots indicate the net effect. Error bars represent the lowest and highest outcomes across the five optimization objectives. (c) Province-level sowing area under the current (left) and the average of five $\mathrm{Y}_{2035}$ optimization objectives (right). Error bars represent the lowest and highest outcomes across the five optimization objectives. 
We assumed that local farmers could perform the attainable improved management practices in each county ${ }^{15}$. The five objectives (scenarios) for optimized crop distribution were separately given the highest priority: minimize $\mathrm{N}$ fertilizer use, minimize $\mathrm{P}$ fertilizer use, minimize irrigation water, minimize $\mathrm{Nr}$ losses, and minimize GHG emissions (Fig. S1). These five objectives were limited by the national production of a certain crop equal to the 2035 demand $\left(\mathrm{Y}_{2035}\right)$. Subsequently, to explore the further mitigation potential from dietary changes, these five objectives were also simulated under the limitation that the national protein production would remain unchanged relative to the 2035 demand $\left(\mathrm{PC}_{2035}\right)$. The sowing area and the volume of irrigation water for each county would not increase relative to 2012 . We set the maximum planting proportion of each crop in the corresponding province as the upper planting limit to limit the flood of superior crops in each county, which could prevent an enormous decline in crop diversity. We also stated that each county could not grow crops that are not currently being grown.

Combining crop redistribution and improved managements can be used to achieve food security in 2035 while offering distinct benefits across agriculture inputs and environmental costs (Fig. 1). These five optimizations producing sufficient food demand $\left(\mathrm{Y}_{2035}\right)$ could save $12 \%$ of the average sowing area (range with five optimizations: $11-13 \%)$, reduce average water irrigation by $22 \%(17-39 \%), \mathrm{N}$ fertilizer use by $35 \%$ (28-41\%), P fertilizer use by $25 \%$ (16-35\%), $\mathrm{Nr}$ loss by $19 \%$ (12-24\%), and GHG emissions by 25\% (15-34\%) relative to 2012 (Fig. 1b). In general, mitigation of environmental pressure through crop redistribution benefited 
from large spatial variation in crop production efficiency across crops and counties (Fig. S2). Such mitigation was achieved mainly from fruits and vegetables, with greater spatial variability, contributing $32 \%$ of the decrease in the sowing area, $26-$ $48 \%$ for N, P, and water use, $45 \%$ for Nr loss, and 59\% for and GHG emissions (Fig. 1b).

Further, $20 \%$ of the sowing area and $24-32 \%$ of the N, P, and water use could be decreased when our target was set to supply sufficient protein in $2035\left(\mathrm{PC}_{2035}\right)$. Additionally, $20 \%$ and $18 \%$ of the $\mathrm{Nr}$ losses and GHG emissions could be further mitigated compared to $\mathrm{Y}_{2035}$ (Fig. 1b). Such mitigation was achieved by increasing the production of rice, peanut, rapeseed, and other crops with higher protein content and lower environmental pressure, while substantially moving away from wheat, fruits, and vegetables with opposite characteristics.

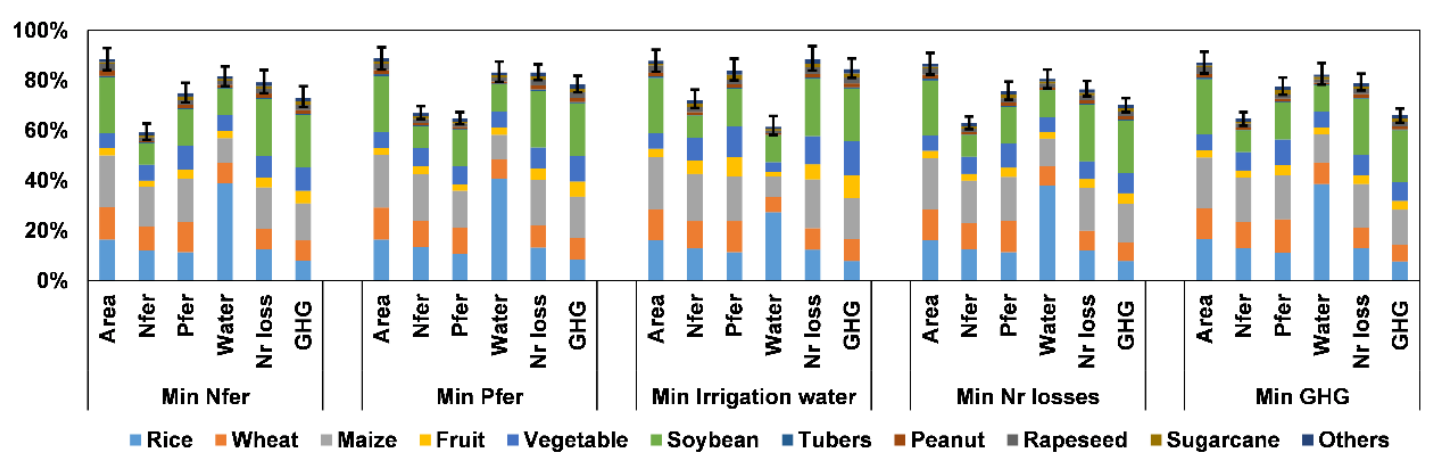

Fig. 2. Agricultural inputs and environmental costs of $Y_{2035}$ relative to the 2012.

On the $y$-axis, $100 \%$ indicates the amount equal to the level in 2012. The error bars reflect the expected lowest and highest estimations under 10,000 Monte Carlo sampling simulations. Area: sowing area; Nfer: nitrogen fertilizer use; Pfer: phosphorus fertilizer use; Water: irrigation water use; GHG: greenhouse gas emission.

The magnitude of these benefits could be increased by selecting certain optimal objectives. For instance, under the scenario that ensures the 2035 food demand 
(Y2035), the magnitude of these benefits could be maximized, such as decreases in $\mathrm{N}$ fertilizer use, P fertilizer use, irrigation water use, $\mathrm{Nr}$ loss, and GHG emissions by $41 \%, 35 \%, 39 \%, 24 \%$, and $34 \%$, respectively, depending on the objective selected

(Fig. 2). Substantial mitigations of input and environmental pressure were predicted to be achieved synchronously. However, it is unrealistic to achieve all objectives simultaneously, for example, the objective to minimize GHG emissions will provide minimal benefits for water use. Hence, the strategy depends on the objectives that are of greatest priority to decision-makers. Other input and environment pressures could also be mitigated, but the magnitude may be weakened.

The characteristics of crop redistribution varied widely among provinces and crops due to the mitigation potential in crop-specific and county-level variation. Modest inter-provincial cropland transfer was shown in cereal crops, but the area of cash crops decreased in all provinces. For example, rice cropland decreased by 1.5 (1.21.8), $1.0(0.2-1.7)$, and $0.8(0.2-1.9)$ million ha in Heilongjiang, Jiangsu, and Guangdong, respectively, but increased by 0.8 (0.6-1.4) and 0.7 (0-2) million ha in Yunnan and Hunan, respectively. The sowing areas of fruits, vegetables, tubers, peanut, rapeseed, sugarcane, and other crops were predicted to decrease by $0.001-2.8$ million ha across all provinces (Fig. 1c). Nearly all crops showed varying degrees of decline in the sowing area; however, soybean will expand by 27.8 (27.7-27.9) million ha due to the substantial increase in feed demand (Fig. 2b). The major increase in soybean occurred in Heilongjiang Province, where the expansion would be 6.4 (6.26.5) million ha ( $23 \%$ of the national expansion of soybean) as a substitute for maize 
(Fig. 1c). This result is consistent with previous findings that Heilongjiang is projected to exhibit the highest increase in soy acreage as simulated through crop models ${ }^{13}$, and shows a significant improvement compare to the year 2017 when soybean import reliance was $90 \%$.
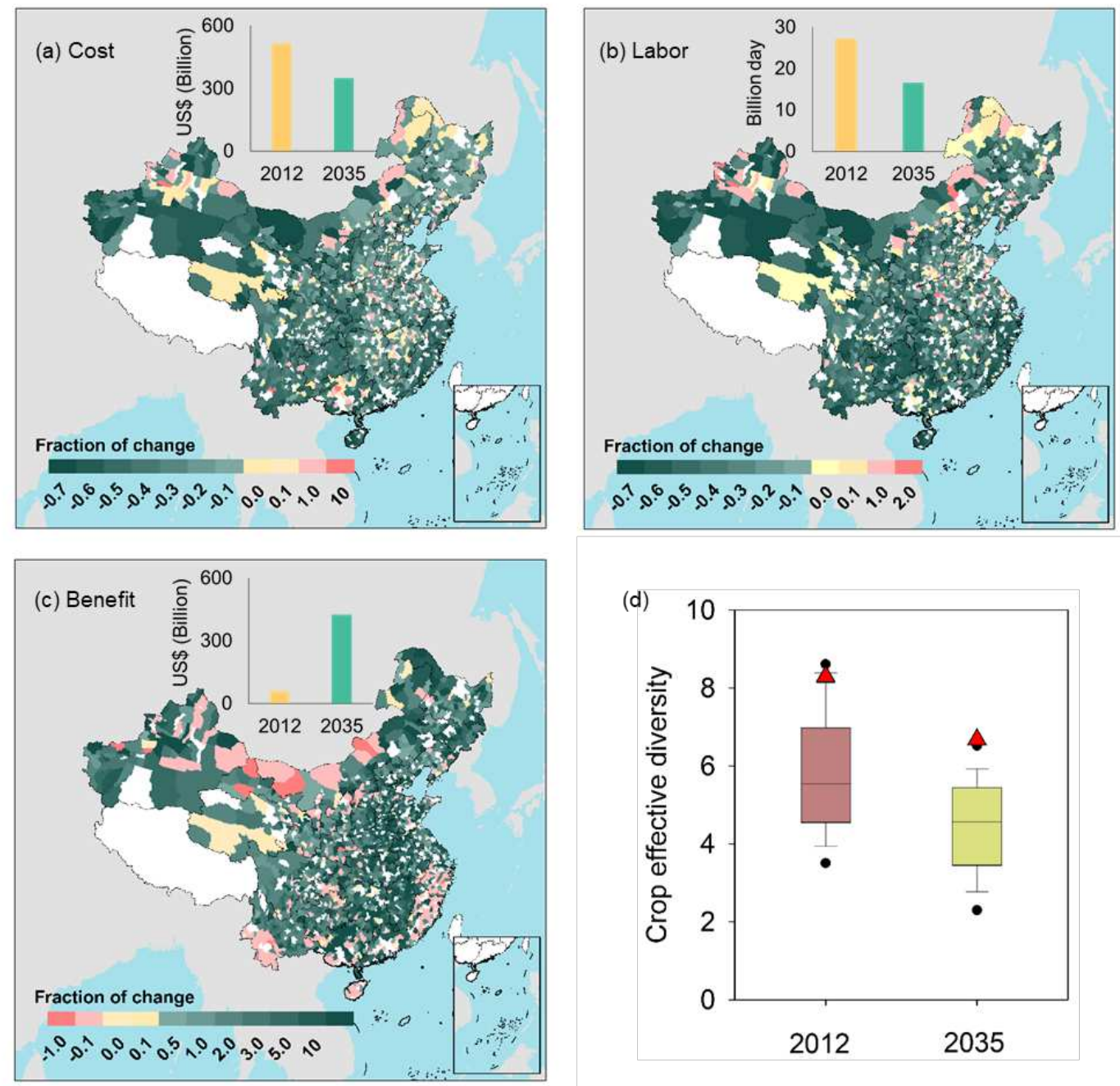

Fig. 3. Variation of agricultural cost (a), labor input (b), farmer's net benefit (c), and crop effective diversity (d) transformed from the current configuration to the optimized crop distribution (the average of five $\mathbf{Y}_{2035}$ optimization objectives). Maps show the fraction of change in each county between the current configuration and the optimized crop distribution, positive (or negative) values indicate multiples of increase (or decrease). Areas in white indicate places with no data. The columns (a-c) represent the national volume of current configuration and optimized crop distribution respectively. The red triangles (d) represent the national crop effective diversity. 
Obstacles to strategy implementation. Despite the multiple co-benefits that we observed, barriers from technical, economic, and ecological factors still exist ${ }^{18}$. The national costs of planting and labor for $\mathrm{Y}_{2035}$ will decrease by $31 \%$ and $37 \%$, respectively, with $86 \%$ of the counties' costs falling by more than $10 \%$ (Fig. 3ab). However, about $5 \%$ of the counties' costs would increase by more than $10 \%$, mainly because cereal crops were converted into cash crops in these counties, such as planting costs averaging $\$ 2,176$ vs. $\$ 7,412$ ha $^{-1}$ for maize vs. fruit ${ }^{23}$. Although the estimated national net economic benefit (gross income minus cost, see Methods) increased from 60 to 426 billion dollars, about $12 \%$ of counties will see decreases of more than $10 \%$ (Fig. 3c). These counties are mainly concentrated in the southwest and eastern coastal areas, due to the decrease in cash crop planting.

Strategies should be adopted to face the various barriers between regions. A guaranteed price that ensures the net income of farmers should be implemented by the government to eliminate the sense of crisis in regions where the planting cost has increased but net income has also increased (scattered throughout all of the provinces). The provision of financial incentives could motivate farmers toward a sustainable strategy in regions where net income has decreased (mainly on the eastern seaboard). Mechanization of farmland should be promoted to improve productivity and reduce labor input, which would decrease the opportunity cost ${ }^{24,25}$. Hence, to achieve sustainable agricultural development, the government must invest to maintain fairness for the farmers around the country. 
The average of $\mathrm{Y}_{2035}$ would decrease effective crop diversity by $25 \%$ at the provincial level and 19\% across the whole country (Fig. 3d). According to a previous study, the stability of the year-to-year food supply may potentially decrease due to decreased crop effective diversity, although the magnitude of such a decline and the key crop groups remain uncertain ${ }^{26}$. It seems an irreconcilable tradeoff between a strategy of intensive crop specialization and effective crop diversity ${ }^{27}$. However, such a tradeoff could be programmed to mitigate in the future if key crop groups that contribute more to stabilize the yield are identified ${ }^{26}$. Additionally, certain counties are predicted to attain more of an environmental benefit than others. For example, although 1,275 counties are predicted to decrease $\mathrm{Nr}$ losses by more than $10 \%$ (mainly in the central and eastern coastal areas of China), 373 counties show increases greater than $10 \%$ (Fig. S11). The areas with increased $\mathrm{Nr}$ loss were mainly in the northeast and the middle and lower reaches of the Yangtze River (Fig. S3). These observations indicate that tradeoffs between sustainable agricultural production and co-prosperity will occur.

The gains in yield, agriculture inputs, and environmental quality that can be achieved by combining enhanced management technologies and crop redistribution are striking, particularly the technologies and knowledge that exist locally in each county. Previous studies conducted on an individual technology provide important, but incomplete insight into the potential for sustainability across large variations in the environment. Our approach based on an integrated and transdisciplinary strategy partially overcomes this challenge and may be better suited to inform targeted 
mitigation policies based on local technologies and knowledge. We found that either implementing optimized crop distribution or closing the yield gap alone could not feed China, even with a large reduction in agricultural inputs and environmental costs (Fig. 1b), indicating the importance of pursuing a mix of strategies toward sustainable development. We also noted that the single-objective optimizations did not produce any tradeoffs among the dimensions that we considered, suggesting that combining enhanced management technologies and crop redistribution consistently improved the outcomes for greater productivity, lower inputs, and less environmental impact.

Despite the prime producers successfully producing more with fewer inputs and lower environmental costs, mobilizing millions of smallholder farmers and broadly encouraging them to enhance their management technologies to approach the prime producers is a major challenge. Agronomic, infrastructural, cultural, and socioeconomic factors affect smallholder productivity ${ }^{28}$. China has made great progress in improving production and environmental performance in recent years through engaging and empowering smallholders ${ }^{17,29}$. For example, Science and Technology Backyard provided a platform for universities, industry, and government to work together to improve farming production and provide a pathway for sustainable agricultural development for farmers ${ }^{30}$.

Sustainable agricultural production could be realized gradually ${ }^{15,17,31}$. A three-step strategy may help the nation develop sustainable management policies by 2035 . The first step is to optimize crop distribution with a $16 \%$ decrease in $\mathrm{Nr}$ loss and a $23 \%$ decrease in GHG emissions (Fig. S5), considering that the strategy does not 
necessarily invoke massive investments in modern technology. The second step is to promote technical improvements to reach $80 \%$ of prime production based on step 1 and achieve a $31 \%$ growth in production relative to step 1 . Finally, full mitigation potential would be realized using an upgrading technique for all producers to achieve the productivity level of the prime producers. In 2015, the Chinese government announced a policy of crop redistribution that converted 3.33 million ha of maize cultivation area to feed crops, such as soybean and grassland ${ }^{32}$. Such a program would help mitigate the overproduction of maize and promote a transition toward more feed self-sufficiency.

Uncertainty in this research. The uncertainties of our estimates are contributed by the quality of the data and the stringency of the constraints for optimization. Uncertainty in the data mainly originates from observation errors, which propagate to $\mathrm{Nr}$ loss and GHG emission estimates. Further uncertainty is related to the constraints of agricultural inputs and environmental costs in linear programming to simulate the optimized crop distribution. The mitigation potential of agricultural input and environmental cost would be reduced if more rigorous constraints are considered, such as spatial natural endowments and environmental thresholds (such as spatially specific planetary boundaries). Additionally, considerable uncertainty exists in the process of improving productivity to the level of the prime producers. We acknowledge that incomplete closing of the yield gap would decrease the rate of food self-sufficiency but also decrease the amount of environmental stress. However, other uncertainties would promote sustainable agricultural development, such as newer crop 
varieties and climate change that would advance crop yield ${ }^{33}$. Also, other measures from the consumption side that would accelerate the process of sustainable agriculture were not considered in this study (e.g., adoption of a healthy diet; reduction of food waste) ${ }^{1,34}$.

Empowering local farmers to attain greater productivity and environmental performance is critical as we pursue an equitable world with a sustainable future ${ }^{30}$. Our detailed analysis provides a valuable addition to the range of viable solutions with a mixture of strategies. Feeding China with fewer inputs and environmental costs requires a coordinated action that must recognize the regional diversity of agricultural systems and improved management practices. The efforts in China toward our solution will make it feasible to achieve sustainable development goals and encourage other developing regions to follow suit on existing cropland. In the future, more detailed and higher resolution data are needed to accurately simulate spatial variation.

\section{Methods}

\section{Configuration of the method}

We constructed an integrated approach depicting agriculture inputs ( $\mathrm{N}$ and $\mathrm{P}$ fertilizer, irrigation water) and environmental costs ( $\mathrm{Nr}$ loss and GHG emission) across 2,036 counties, and exploring how food demand in 2035 can be met sustainably through attainable improved managements and crop redistribution. The food demand in 2035 was firstly simulated using the NUFER (Nutrient flows in Food chains, Environment, and Resource use) model ${ }^{35}$. Then, crop-specific county-level attainable improved managements (including potential yield and agriculture input) were estimated through 
a total of 11.1 million farmer survey in 2,036 counties ${ }^{15}$. The corresponding environmental cost were calculated through a Random Forest regression model and meta-analysis by using data from statistical databases and literature related to on-farm field experiments. Next, a linear optimization method was used to simulate the optimized crop distribution in 2035 based on the attainable improved managements under specific objectives and constraints.

\section{Food demand in 2035}

The quantity of national food required in 2035 was estimated using the NUFER model ${ }^{36}$. The NUFER model quantifies food, animal feed, industrial products, and food waste within the whole food production-consumption chain. The consumption of plant- and animal-based food was depended on the changing rural and urban populations and diets. The feed requirements were estimated based on human consumption of animal products. Feed requirements were estimated from the net energy of animals, as a function of animal category and production level, using the NUFER model. We adopted a middle-of-the-road estimate that assumed a Chinese population of 1.46 billion people with an urbanization rate of $72 \%$ in 2035 (Table S1). We asserted that the dietary consumption pattern of urban and rural residents will remain the same as the baseline year of 2017, but some of the rural residents will become urban residents by 2035 . Therefore, more animal food, fruit, and vegetable production are required to meet the diet demand; correspondingly, more maize and soybean are required to feed the increased number of livestock (Table S2).

\section{Datasets.}


Production and agricultural inputs of attainable improved managements. A total of 11.1 million producers in 2,036 counties were surveyed, representing $>95 \%$ of the cropland in China. Face-to-face interviews were conducted by local agricultural extension agents, using a standardized questionnaire consisting of close-ended questions to obtain information on crop type, yields, and nutrient inputs of these producers ${ }^{17}$. Fifty-three crops were planted by these producers, including rice, wheat, maize, fruits, vegetables, soybean, tuber, peanut, rapeseed, sugarcane, and others (Table S1). The grain portion of rice, wheat, and maize had 15\% moisture. The yield for the other eight crop groups (fruits, vegetables, soybean, tubers, peanut, rapeseed, sugarcane, and other crops) was the fresh amount of the economic portion of the plant.

Prime producers were defined as the surveyed producers that were ranked high in crop yield and $\mathrm{N}$ efficiency. The prime $10 \%$ of the producers from the 11 crop groups were the top $68-100^{\text {th }}$ percentile in crop yield and $\mathrm{N}$ efficiency ${ }^{15}$. To ensure adequate numbers of prime producers, at least 50 producers were subjected to ranking for each crop in each county. The average yield and agriculture input of these prime $10 \%$ producers were defined as the attainable improved managements.

Agricultural inputs in this study included sowing area, total N (including fertilizer, manure, deposition, irrigation, and biological fixation) and $\mathrm{P}$ (including fertilizer and manure) input, and irrigation water. The county-level sowing area of the $11 \mathrm{crop}$ groups in 2012 was obtained from the National Bureau of Statistics of China ${ }^{22}$ to describe the current crop configuration in each county. Data on crop yield, chemical $\mathrm{N}$ 
and $\mathrm{P}$ application rates, and application rates of specific crops were sourced from the farmer survey. The total $\mathrm{N}$ and $\mathrm{P}$ inputs were calculated as follows (set $\mathrm{N}$ as an example; equation (1)):

$$
N_{\text {total }}^{i}=N_{\text {fer }}^{i}+N_{\text {man }}^{i}+N_{\text {dep }}^{i}+N_{\text {irr }}^{i}+N_{\text {fix }}^{i}
$$

where superscript $i$ indicates crop group $i ; N_{\text {fer }}$ is $\mathrm{N}$ from a fertilizer application, $N_{\text {man }}$ is $\mathrm{N}$ from manure use; $N_{d e p}$ is $\mathrm{N}$ from deposition; $N_{i r r}$ is $\mathrm{N}$ from irrigation; and $N_{f i x}$ is $\mathrm{N}$ from biological fixation.

The amounts of $\mathrm{N}$ and $\mathrm{P}$ from deposition, irrigation, and biological fixation were obtained using the $\mathrm{N}$ and $\mathrm{P}$ input factors multiplied by the corresponding sowing area (see Supplementary Material). The amount of irrigation water was obtained from Zhou et al. ${ }^{6}$, we extracted the year 2012 and downscaled the irrigation water use to the county-level for the 11 crop groups with the corresponding irrigated area.

Environmental costs. Environmental costs in this study included $\mathrm{Nr}$ loss (including $\mathrm{N}_{2} \mathrm{O}, \mathrm{NH}_{3}$, and $\mathrm{NO}_{3}{ }^{-}$) and cropland $\mathrm{GHG}$ emission. To build a database of field research findings on $\mathrm{Nr}$ loss from croplands in China, we conducted a literature search using Web of Science and the China National Knowledge Infrastructure for relevant articles published between January 1995 and August 2018. In total, 675 peer-reviewed studies contributing 4,272 observations (2,772 from 289 studies on $\mathrm{N}_{2} \mathrm{O}, 785$ from 299 studies on $\mathrm{NH}_{3}$, and 715 from 218 studies on $\mathrm{NO}_{3}{ }^{-}$; see Supplementary Materials) were identified. The emission factor (EF) was derived as the calculated amount of $\mathrm{N}_{2} \mathrm{O}, \mathrm{NH}_{3}$, and $\mathrm{NO}_{3}{ }^{-}$divided by the amount of $\mathrm{N}$ applied.

The EF values for the 11 crops were determined at the county level. We constructed 
an RF regression model using parameter measurements compiled from 675 studies mentioned above. Data were processed in three steps. First, the model randomly selected a bootstrap sample of observations (in-bag data), which was equivalent to the entire set of observations, along with replacements. About $37 \%$ of the initial observations were not selected (out-of-bag [OOB] data). A regression tree was constructed based on the in-bag data and the $m_{\text {try }}$ variables (where $m_{\text {try }}$ is the number of variables randomly sampled as candidates at each split in the tree). All splits in the tree were examined using predictor variables, and the best split at each step was determined to build the regression tree. The mean square error of the prediction (MSEоOв) was calculated as follows (equation (2)):

$$
M S E_{O O B}=\frac{1}{n} \sum_{i=1}^{n}\left(y_{i}-\hat{y}^{O O B}\right)^{2}
$$

where $y_{i}$ is observation $\mathrm{i}$ and $\hat{y}^{O O B}$ is the predicted OOB value. The OOB observation $\mathrm{i}$ in the regression tree represents the mean $\mathrm{Nr}$ loss for the in-bag observations at the same terminal node.

$\mathrm{Nr}$ EFs were the dependent variables in the RF regression model. RF modeling with 10-fold cross-validation identified the following major factors associated with $\mathrm{Nr}$ losses: climate (precipitation, potential evapotranspiration, and mean temperature during the growth period) and soil (sand and organic matter content). The dataset was evaluated by dividing it into ten subsets of equal size; seven subsets were used for modeling and three were used for testing with the RF model.

The amounts of $\mathrm{N}_{2} \mathrm{O}, \mathrm{NH}_{3}$, and $\mathrm{NO}_{3}{ }^{-}$lost were calculated as equation (3):

$$
N r \operatorname{loss}_{i}=\left(E F_{i}^{\mathrm{N}_{2} \mathrm{O}}+E F_{i}^{N \mathrm{H}_{3}}+E F_{i}^{N \mathrm{O}_{3}^{-}}\right) * N_{\text {total }}
$$


where $E F_{i}^{N_{2} \mathrm{O}}$ is the loss factor of $\mathrm{N}_{2} \mathrm{O}$ and $N_{\text {total }}$ is total $\mathrm{N}$ input in cropland.

We further calculated GHG emissions in the cropland as equation (4):

$$
\mathrm{GHG}=\left(\mathrm{N}_{2} \mathrm{O}+\mathrm{NH}_{3} * 0.01+\mathrm{NO}_{3}^{-} * 0.0075\right) * 265 * 44 / 28
$$

\section{Optimizations and constraints in 2035}

We considered five different optimization objectives for China's crop production respectively, each one is accorded highest priority: 1) minimize national $\mathrm{N}$ fertilizer use, 2) minimize national $\mathrm{P}$ fertilizer use, 3) minimize national irrigation water, 4) minimize $\mathrm{Nr}$ loss, and 5) minimize GHG emissions.

A linear optimization procedure was used to find the best appropriate crop configuration that fulfill the food demand of China, while minimizing the five objectives above respectively. Optimization was performed using MATLAB software by the following minimizing equation (5):

$$
\min \sum_{i, j=1}^{m, n} S A^{i, j} * I^{i, j}
$$

Where $S A^{i, j}$ is the sowing area of county i and crop j, and $I^{i, j}$ represents the intensity of $\mathrm{N}, \mathrm{P}$ fertilizer use, irrigation water, $\mathrm{Nr}$ loss and GHG emission of county i and crop j respectively.

The cropland distribution is optimized for each crop groups and in each county by using the objective function equation 6 and under the following constraints (equation 6-10): (1) The sowing area for each county will not increase relative to 2012 (equation 6). This constraint was used to prevent any cropland expansion under optimization.

(2) Irrigation water for each county will not increase relative to 2012 (equation 7). This constraint was used to prevent further pressure on the water resources. (3) To 
prevent an expanded geographical range for any of the crops and confined the crop production to counties with local knowledge and suitable soil and climate condition. We set the constraint that all county could not grow crops that are not currently being grown (equation 8). (4) To prevent the counties from overplanting superior crops after optimization, which would lead to a significant reduction in crop diversity. We first select the maximum sowing area proportion of each crop from counties in each province, then set it as the upper limit for the corresponding province, the other county will not exceed the upper limit (equation 9). (5) The national production of a certain crop equal to the demand in $2035\left(\mathrm{Y}_{2035}\right)$ or the national protein production equal the protein demand in $2035\left(\mathrm{P}_{2035}\right)$ (equation 10). These two constraints, which are also two scenarios, were set to evaluate the mitigation potential of dietary changes in 2035. $\mathrm{Y}_{2035}$ assumes that existing diets will not change in 2035. $\mathrm{P}_{2035}$ was investigated to explore the mitigation potential of dietary change. The equation can be expressed as follows:

$$
\begin{gathered}
S A_{o p t}^{i}<S A_{c}^{i} \\
\sum_{j=1}^{n} S A_{o p t}^{i, j} * I_{\text {water }}^{i, j}<\sum_{j=1}^{n} S A_{c}^{i, j} * I_{\text {water }}^{i, j} \\
S A_{o p t}^{i, j}= \begin{cases}0 & \text { if } S A_{c}^{i, j}=0 \\
S A_{\text {opt }}^{i, j} & \text { if } S A_{c}^{i, j} \neq 0\end{cases} \\
S A_{o p t}^{i, j} /_{S A_{c}^{i} \leq \max _{\text {in province }}\left(S A_{c}^{i, j} / S A_{c}^{i}\right)} \\
\sum_{i=1}^{m} Y_{o p t}^{i, j}=Y_{2035}^{j}\left(\text { scenario: } \mathrm{Y}_{2035} \text { ) or } \sum_{i=1}^{m} P_{o p t}^{i, j}=P_{2035} \text { (scenario: } \mathrm{P}_{2035}\right. \text { ) }
\end{gathered}
$$

where the subscripts opt and $c$ represents the optimized crop distribution and the current crop distribution, and the superscripts $i$ and $j$ represent the county $\mathrm{i}$ and crop $\mathrm{j}$, 
$S A$ is the sowing area (ha), $I_{\text {water }}^{i, j}$ is irrigation water intensity of county i and crop $\mathrm{j}$, $Y$ is crop production $(\mathrm{kt}), P$ is protein production $(\mathrm{kt})$, respectively.

\section{Cost, benefit, labor and crop effective diversity}

Total agricultural costs in this study were defined as the sum of material (including seed, fertilizer, manure, pesticides, and other materials), labor, and land cost. The amounts were obtained using the cost of the materials, labor, and land multiplied by the corresponding sowing area. The benefit of farmers in this study were defined as the sales revenue (defined as the selling price multiplied by crop production) minus the total agriculture cost. Cost of materials, labor, and land and the selling price were sourced from the National Agricultural Products Cost-Benefit Compilation of Information ${ }^{23}$. Due to the lack of county-level cost and selling price factors, we used provincial-level data instead. The calculations are list in equation (11-13):

$$
C_{\text {total }}^{i, j}=S A^{i, j} *\left(C_{\text {material }}^{i, j}+C_{\text {labor }}^{i, j}+C_{\text {land }}^{i, j}\right)
$$

where superscripts $i$ and $j$ represent the county $\mathrm{i}$ and crop $\mathrm{j} ; C_{\text {total }}^{i, j}$ is total cost (US dollar); $S A^{i, j}$ is the sowing area (ha); and $C_{\text {material }}^{i, j}, C_{\text {labor }}^{i, j}$, and $C_{\text {land }}^{i, j}$ are cost factors for materials, labor, and land cost respectively (US\$ ha $\left.{ }^{-1}\right)$.

$$
\begin{aligned}
& B^{i, j}=C_{\text {total }}^{i j}-S R^{i, j} \\
& S R^{i, j}=S P^{i, j} * P^{i, j}
\end{aligned}
$$

where $B^{i, j}$ is the benefit of county $i$ and crop j, $S R^{i, j}$ is sales revenue (US\$), $S P^{i, j}$ is selling price (US $\$$ ton $^{-1}$ ), and $P^{i, j}$ is crop production (ton).

The amount of labor was obtained using the labor input factor multiplied by the corresponding sowing area. Labor input factors were sourced from the National 
Agricultural Products Cost-Benefit Compilation of Information ${ }^{23}$. Calculations are as equation (14):

$$
L A^{i j}=S A^{i j} * L F^{i j}
$$

where superscript $i j$ indicates crop group $\mathrm{i}$ in county $\mathrm{j}, L A^{i j}$ is labor input (per), and $L F^{i j}$ is the labor input factor $\left(\right.$ per ha $\left.^{-1}\right)$.

We also calculated effective crop diversity at the county, provincial, and national levels. We used the proportion of each crop group in the total sowing area (rice, wheat, maize, fruits, vegetables, soybean, tuber, peanut, rapeseed, sugarcane, and others) to calculate the Shannon diversity index and thus the effective diversity of the crop groups. The calculation is as equation (15):

$$
H^{\prime}=-\sum_{i=1}^{n}\left(p_{i} * \ln \left[p_{i}\right]\right)
$$

where $p_{i}$ is the proportion of total national cropland dedicated to crop i, and $n$ is the total number of crop groups.

\section{Uncertainty estimation}

A Monte Carlo simulation was used to estimate the overall uncertainty for predicting crop distribution and mitigation potentials. The distribution of each input parameter for all crop distributions in the random sampling procedure for the Monte Carlo simulations is described using mean values and standard deviations. All parameters followed independent normal distributions with $10 \%$ standard deviation. We simulated the mitigation of agriculture input and environment costs based on the predicted crop distribution using 10,000 iterations and calculated the mean and $2.5 \%$ and $97.5 \%$ quantiles with the $95 \%$ prediction interval. 


\section{Data availability}

The data sets generated and/or analyzed during this study are available upon request from the corresponding authors.

\section{Code availability}

All computer codes generated during this study are available from the corresponding author upon reasonable request.

\section{References}

1. Clark, M. A., Springmann, M., Hill, J. \& Tilman, D., Multiple health and environmental impacts of foods. Proc. Natl Acad. Sci. USA. 116, 23357 (2019).

2. Davis, K. F. et al., Assessing the sustainability of post-Green Revolution cereals in India. Proc. Natl Acad. Sci. USA. 116, 25034 (2019).

3. van Dijk, M., Morley, T., Rau, M. L. \& Saghai, Y., A meta-analysis of projected global food demand and population at risk of hunger for the period $2010-2050$. Nat. Food, 2, 494 (2021).

4. Grassini, P., Eskridge, K. M. \& Cassman, K. G., Distinguishing between yield advances and yield plateaus in historical crop production trends. Nat. Commun. 4 (2013).

5. FAO, http://www.fao.org/faostat/en/\#home. Accessed 5 September 2021.

6. Zhou, F. et al., Deceleration of China' s human water use and its key drivers. Proc. Natl Acad. Sci. USA. 117, 7702 (2020). 
7. Wu, H. et al., Estimating ammonia emissions from cropland in China based on the establishment of agro-region-specific models. Agr. Forest Meteorol. 303, 108373 (2021).

8. Yue, Q. et al., Deriving Emission Factors and Estimating Direct Nitrous Oxide Emissions for Crop Cultivation in China. Environ. Sci. Technol. 53, 10246 (2019).

9. Hoekstra, A. Y. \& Wiedmann, T. O., Humanity's unsustainable environmental footprint. Science, 344, 1114 (2014).

10. O Neill, D. W., Fanning, A. L., Lamb, W. F. \& Steinberger, J. K., A good life for all within planetary boundaries. Nat. Sustain. 1, 88 (2018).

11. Steffen, W. et al., Planetary boundaries: Guiding human development on a changing planet. Science, 347, 1259855 (2015).

12. Gerten, D. et al., Feeding ten billion people is possible within four terrestrial planetary boundaries. Nat. Sustain. 3, 200 (2020).

13. Liu, Z. et al., Optimization of China' s maize and soy production can ensure feed sufficiency at lower nitrogen and carbon footprints. Nat. Food, 2, 426 (2021).

14. Mueller, N. D. et al., Closing yield gaps through nutrient and water management. Nature, 490254 (2012).

15. Zhang, Q. et al., Outlook of China's agriculture transforming from smallholder operation to sustainable production. Glob. Food Secur-Agr. 26, 100444 (2020).

16. Chen, X. et al., Producing more grain with lower environmental costs. Nature, 514, $486(2014)$.

17. Cui, Z. et al., Pursuing sustainable productivity with millions of smallholder 
farmers. Nature, 555, 363 (2018).

18. Davis, K. F., Rulli, M. C., Seveso, A. \& D Odorico, P., Increased food production and reduced water use through optimized crop distribution. Nat. Geosci. 10, 919 (2017).

19. Chen, X. et al., Integrated soil-crop system management for food security. Proc. Natl Acad. Sci. USA. 108, 6399 (2011).

20. Ju, X., Gu, B., Wu, Y. \& Galloway, J. N., Reducing China’ s fertilizer use by increasing farm size. Global Environ. Chang. 41, 26 (2016).

21. UN (United Nations) Department of Economic and Social Affairs, Population Division (2019). World Population Prospects 2019, Online Edition. Rev. 1.

22. NBSC (National Bureau of Statistics of China), National data. https://data.stats.gov.cn/. Accessed 12 Sep. 2021. (in Chinese).

23. NDRC (National Development and Reform Commission), 2013. China agricultural products cost-benefit compilation of information. Beijing, China. https://en.ndrc.gov.cn/. Accessed 15 Sep. 2021. (in Chinese).

24. Bai, X., Shi, P. \& Liu, Y., Society: Realizing China's urban dream. Nature, 509, $158(2014)$.

25. Fan, S., Brzeska, J., Keyzer, M. \& Halsema, A., From Subsistence to Profit: Transforming Smallholder Farms. (Inter. Food Policy Res. Inst., Washington, 2013).

26. Renard, D. \& Tilman, D., National food production stabilized by crop diversity. Nature, 571, 257 (2019). 
27. Sirami, C. et al., Increasing crop heterogeneity enhances multitrophic diversity across agricultural regions. Proc. Natl Acad. Sci. USA. 116, 16442 (2019).

28. Wu, Y. et al., Policy distortions, farm size, and the overuse of agricultural chemicals in China. Proc. Natl Acad. Sci. USA. 115, 7010 (2018).

29. Zhang, F., Chen, X. \& Vitousek, P., An experiment for the world. Nature, 497, 33 (2013).

30. Zhang, W. et al., Closing yield gaps in China by empowering smallholder farmers. Nature, 537, 671 (2016).

31. Yin, Y. et al., A steady-state $\mathrm{N}$ balance approach for sustainable smallholder farming. Proc. Natl Acad. Sci. USA. 118, e2106576118 (2021).

32. MOA (Ministry of Agriculture of the People's Republic of China), 2017. http://www.moa.gov.cn/. (in Chinese).

33. Ying, H. et al., Newer and select maize, wheat, and rice varieties can help mitigate N footprint while producing more grain. Global Change Biol. 25, 4273-4281 (2019).

34. $\mathrm{Hu}, \mathrm{Y}$. et al., Food production in China requires intensified measures to be consistent with national and provincial environmental boundaries. Nat. Food, 1, 572 (2020).

35. Ma, L. et al., Environmental Assessment of Management Options for Nutrient Flows in the Food Chain in China. Environ. Sci. Technol. 47, 7260 (2013).

36. Ma, L. et al., Exploring Future Food Provision Scenarios for China. Environ. Sci. Technol. 53, 1385 (2018). 


\section{Acknowledgments}

We acknowledge all those who provided local assistance and technical services involving the farmer survey. This work was financially supported by the Science and Technology Plan Project of Qinghai Province (2019-NK-A11-02), the Taishan Scholarship Project of Shandong Province (No. TS201712082), and Chinese Universities Scientific Fund (No. 2021TC080).

\section{Author Contributions}

Z.C., Y.Y., and Z.W. designed the study. Z.C. led the study. Z.W. and Y.Y. contributed to the method construction, data analysis and writing. Y.W., X.T., H.Y., and Q.Z. provided the emission data. Y.X., F.Z., M.D., L.M., and F.Z. have revised the study.

\section{Competing interests}

The authors declare no competing interests.

\section{Additional information}

Reprints and permissions information are available at www.nature.com/reprints. The authors declare no competing financial interests. Readers are welcome to comment on the online version of the paper. Correspondence and requests for materials should be addressed to Z.C. (cuizl@cau.edu.cn) 


\section{Supplementary Files}

This is a list of supplementary files associated with this preprint. Click to download.

- Referencelist.pdf

- Supplementaryinformation.pdf 